\title{
Influence of Process Parameters on Ceroxide Formation in Low-Carbon Steels
}

\author{
Alexis Vaucheret ${ }^{\mathrm{a}, \mathrm{b}}$, Cécile Nicoli ${ }^{\mathrm{a}, \mathrm{b}, \mathrm{c}}$, Jean-François Carton ${ }^{\mathrm{c}}$, Philippe Jacquet ${ }^{\mathrm{a}, \mathrm{b}}$ \\ aUniversité de Lyon, ECAM Lyon, INSA-Lyon, LabECAM, F-69005 Lyon, France \\ ${ }^{b}$ LaBoMaP, Arts et Métiers ParisTech, 71250 Cluny, France \\ c SAFE Metal, 1 Boulevard de la Boissonnette, 42110 Feurs, France \\ *e-mail: alexis.vaucheret@ecam.fr
}

Received: 22 Sptember 2017/Accepted: 8 November 2017/Published online: 31 January 2018

This article is published with open access at AGH University of Science and Technology

\begin{abstract}
Ceroxides are surface defects caused by a mold-metal reaction during the casting process of steels. This type of defect may affect a large area, but it is located only on the skin of the parts. It does not affect the core of the parts nor its mechanical properties. Nevertheless, ceroxides induce a lack of material on the surface, forming a kind of crater and needing complementary surfacing.

The defect is also composed by several non-metallic inclusions containing $\mathrm{Al}, \mathrm{Mg}$, $\mathrm{Si}$ and $\mathrm{O}$. An EDX analysis by mapping show these elements involved in the mold-metal reaction. The presence of these oxides could confirm the hypothesis of the deoxidizer reoxidation found in the bibliography.

To better understand the specific conditions of ceroxide formation, the first step was to find of way to generate systematically this defect at each casting. Two patterns with different filling rate were designed, simulated on Quikcast and tested. The pattern with turbulent filling rate allowed the formation of ceroxide at each casting and so was used during this study. This result shows that the filling rate of the mold could be considered as a first order parameter in ceroxide formation. Then, a specific experimental set up was designed to characterize this defect. The analysis of the defect was done for sizing it: surface and depth. Finally, some key parameters on defect formation were determined like the nature of deoxidizer or the amount of oxygen in the mould. Some laboratory tests were lead to show the influence of these parameters by characterization of the casted parts in comparison with a reference sample. This study allowed us to find process parameters responsive of ceroxide formation and to propose some way of improvement to reduce the size and the occurrence of ceroxides.
\end{abstract}

\section{Keywords:}

ceroxide, low carbon steel, mold/metal reaction, deoxidation

\section{INTRODUCTION}

Ceroxide is a specific default that appears on the surface of steel-casted parts. It probably results from a mold/metal reaction of re-oxidation of the deoxidizer used for steel elaboration during pouring. A ceroxide looks like a kind of crater containing non-metallic materials. Even if ceroxides do not affect the mechanical properties of the casted parts, the lack of material induced by its formation orders foundries to make a complementary surfacing by welding. So, this study tries to find solutions to avoid ceroxide formation by modifying the process foundry parameters of steel part elaboration.

To do this, this paper will start by describing ceroxides and their conditions of formation. Before testing the different process parameters that could influence ceroxide apparition, the experimental protocol will be presented; most particularly, the method of obtaining ceroxides and the characterization methods. Then, the process parameters chosen will be described before presenting the results of this study. To conclude, a discussion of the results will be done.

\section{DEFINITION OF CEROXIDE DEFECT}

This defect is located on the upper surface of a part [1] and does not affect its core nor its mechanical properties. It is shaped like a circular crater with some bubbles inside or in its outlying area (see Figure 1).

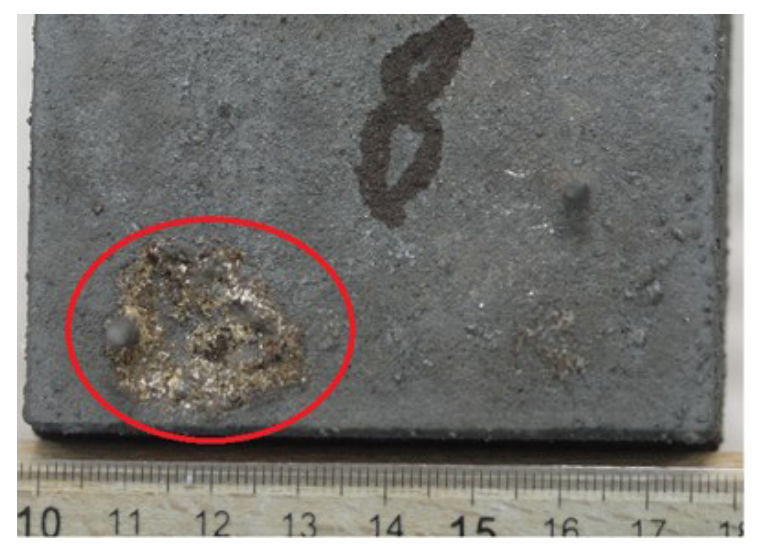

Fig. 1. Top view of ceroxide defect 
The name ceroxide comes from "ceramic oxides" and looks like a large inclusion containing non-metallic materials [2, 3]; according to Campbell [2], ceroxides contain chemical elements such as $\mathrm{Al}, \mathrm{Mn}, \mathrm{Si}$, and $\mathrm{O}$ in the case of carbon steels.

Figures 2 and 3 present cross-section examinations with a scanning electronic microscope outside the ceroxide zone (Fig. 2) and inside (Fig. 3). Outside, the surface seems very "clean," whereas a several-micrometer-thick layer is observed inside the crater.

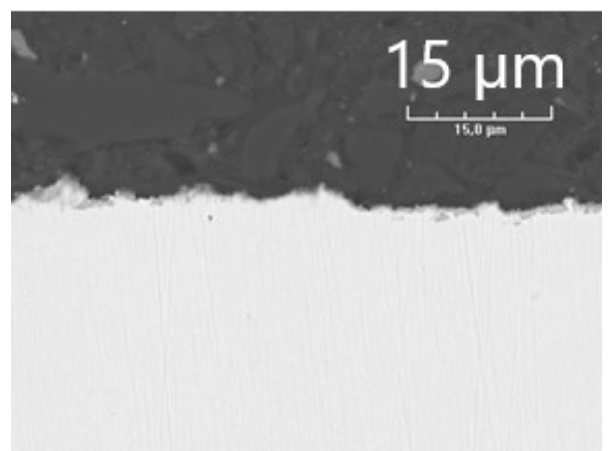

Fig. 2. Cross-section view outside ceroxide zone (SEM - BSE)

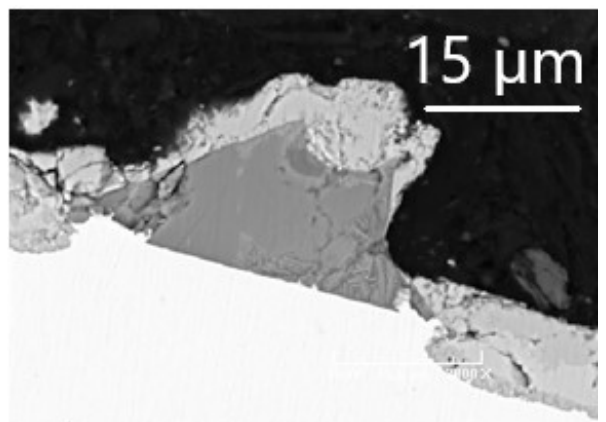

Fig. 3. Cross-section view inside ceroxide zone (SEM - BSE)

Some chemical analyses by means of EDS have been realized on the cross section presented in Figure 3. The mapping results are presented in Figures 4a through 4e. The top layer consists of iron oxides, and a mixed oxide (containing $\mathrm{Al}$, $\mathrm{Mn}$, and $\mathrm{Si}$ ) is trapped between this top layer and the steel substrate.

Contrary to another mold-metal defect known as a "scab" (which presents a soaking of the metal inside the sand [4]), ceroxides look like a lack of material. The presence of numerous oxides $\left(\mathrm{SiO}_{2}, \mathrm{MnO}, \mathrm{FeO}, \mathrm{Al}_{2} \mathrm{O}_{3}\right)$ [5] seems due to a chemical reaction between the oxygen from the atmosphere and deoxidizers (such as aluminum) introduced in the liquid steel before pouring $[3,6]$. Mahaney [7] shows that, among the casting defects that have the aspect of ceroxides, approximately half of them are linked to re-oxidation products. The parameters that appear to play a role in the occurrence of such a defect according to $[5,8,9]$ are the pouring temperature, filling rate of the mold, chemical reactivity of the deoxidizers, and presence of moisture inside the sand of the mold.

The resolution of this defect consists of a surfacing of the casted parts, which may cost a lot (especially if there are many of them). a)

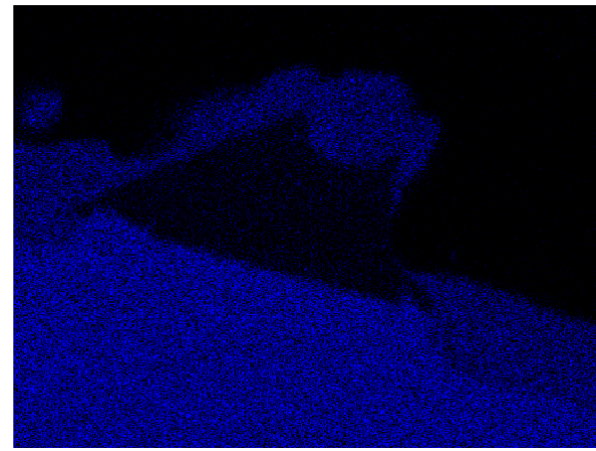

b)

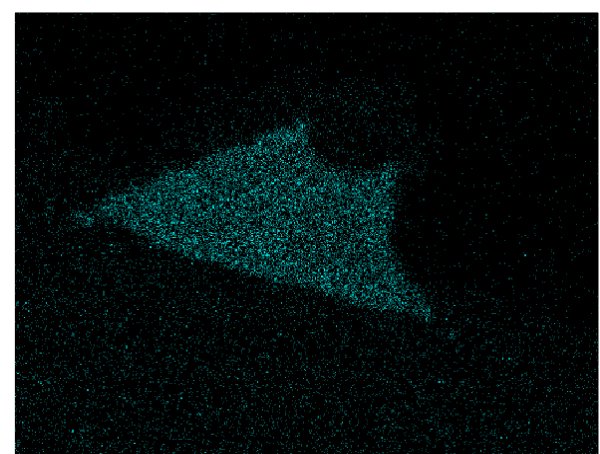

c)

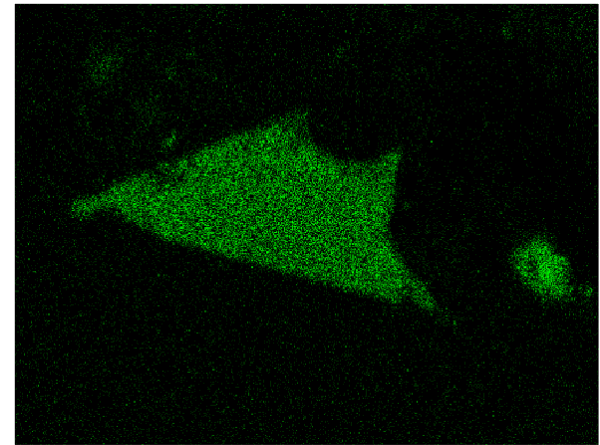

d)

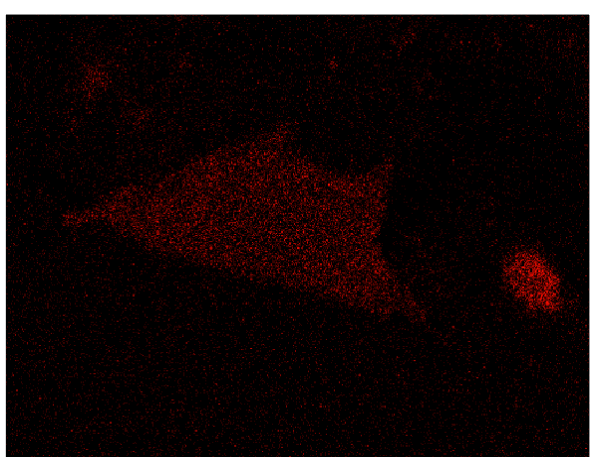

e)

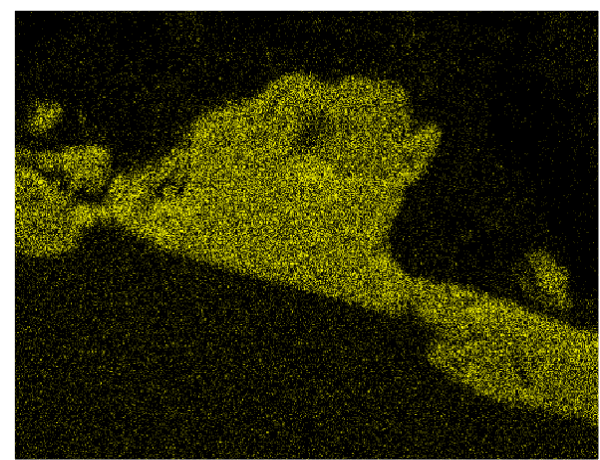

Fig. 4. EDS analysis - mapping of different chemical elements: a) Iron; b) Manganese; c) Silicone; d) Aluminum; e) Oxygen 


\section{DESCRIPTION OF EXPERIMENTAL PROTOCOL}

\subsection{Patterns}

A specific experimental setup has been designed for this study. It includes the part where the ceroxide may appear (1), a feeder (2), afunnel (3), and an area for flow regulation (4). The size of this last part is adjustable, and a filter can be added in order to investigate different flow rates (from laminar to turbulent). To test different flow rates, the launders section can be changed, and a filter can be added. The laminar and turbulent patterns as well as their dimensions are presented in Figure 5. The part and the feeder are the same for both patterns. The feeder was sized to avoid shrinkage in the part and minimize the yield. The part measured $80 \times 80 \times 40 \mathrm{~mm}$. The part's dimensions were defined to have enough metal to create a reaction with the mold and to be small enough to be poured in a laboratory. The volume of the spray was approximatively one liter.

a)

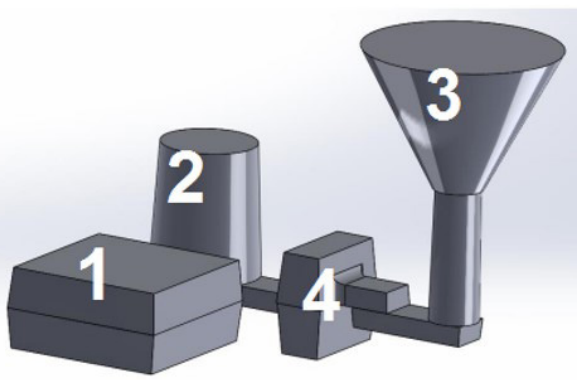

b)

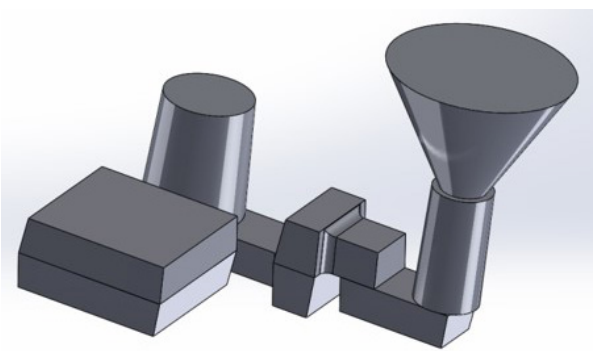

Fig. 5. Design of experimental setup: a) pattern with laminar flow rate; b) pattern with turbulent flow rate

Numerical simulations using Quikcast software were done for each pattern to check the differences in flow rates. The results are presented in Figures 6 and 7. It is possible to see that the filling velocity is doubled with the turbulent pattern. Moreover, the laminar pattern allowed for a filling rate and velocity that were in accordance with those used in industrial foundries.

The first set of tests (repeatability tests) showed that ceroxides systematically appeared in the case of turbulent flows and not in the case of laminar flows. This phenomenon, also noticed by W.S. Lyman [5], indicates that the flow is a "first order" parameter. In order to show the influence of other parameters on the occurrence of ceroxides, it was decided to realize all of the following experiments with a turbulent flow. During the five repeatability tests, the ranges of the surface impacted by ceroxides varied between
10 and $82 \%$ and the depths between 2 and $9 \mathrm{~mm}$. The range of variation is quite important. For this study, only the lowest value of the repeatability tests will be considered to control the influence of each parameter. For each parameter tested, if the results given by ceroxide characterization are lower than those minimum values, it will be considered as an improvement compared to the reference tests.

a)

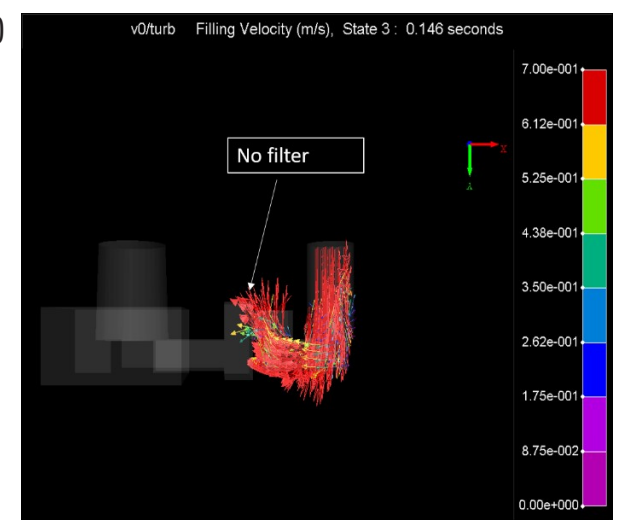

b)

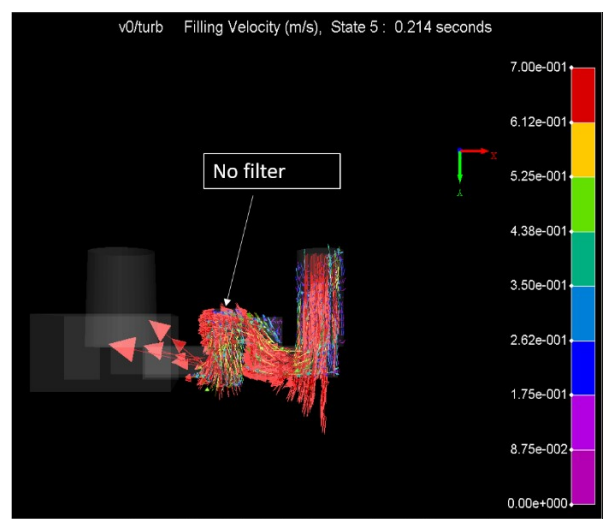

c)

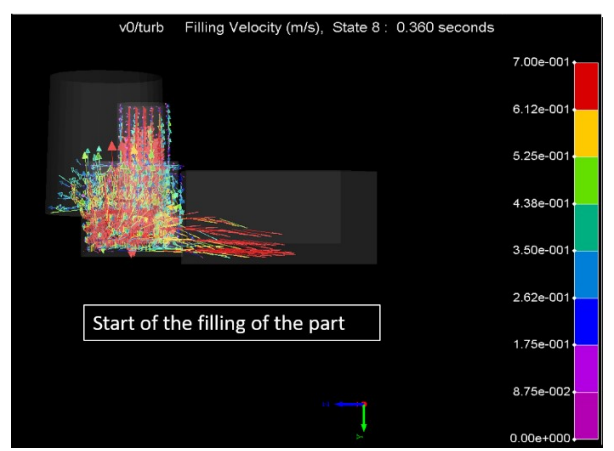

d)

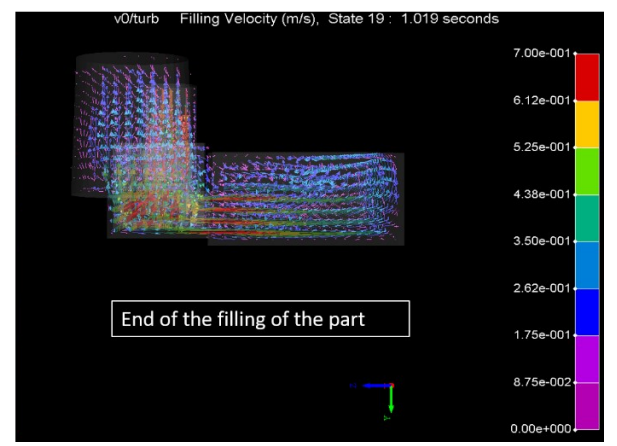

Fig. 6. Filling velocity of turbulent pattern obtained by simulation on Quikcast: a) at the beginning of the casting; b) in the launders; c) at the beginning of the filling of the part; d) at the end of the filling of the part 
a)

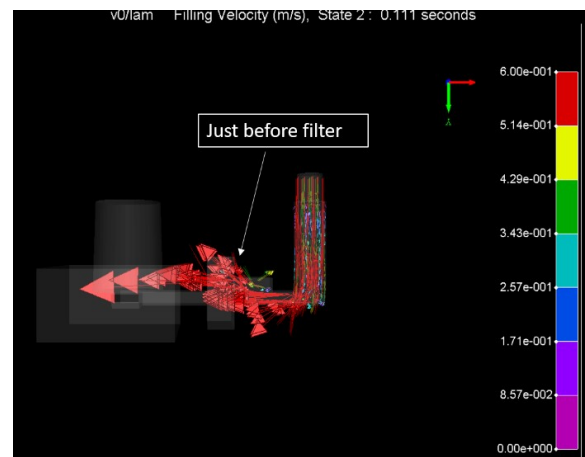

b)

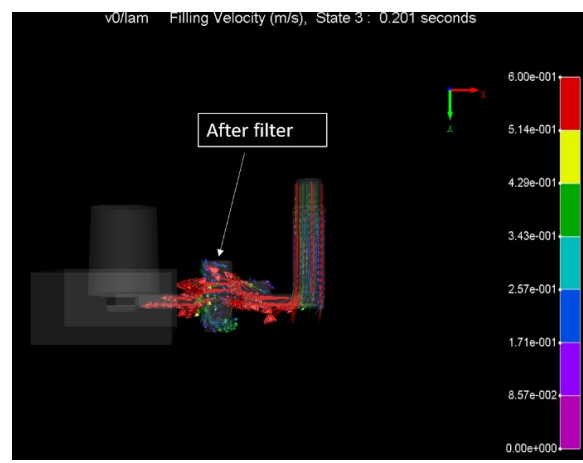

c)

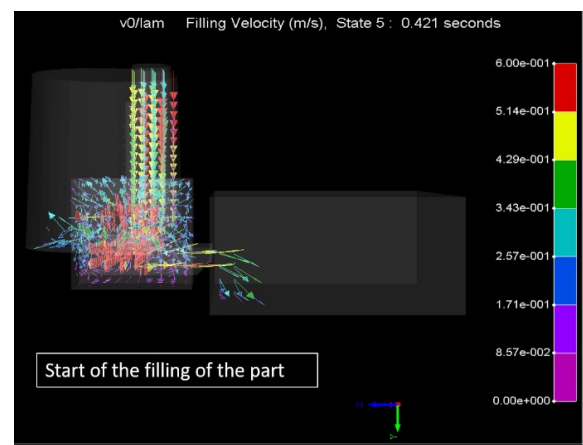

d)

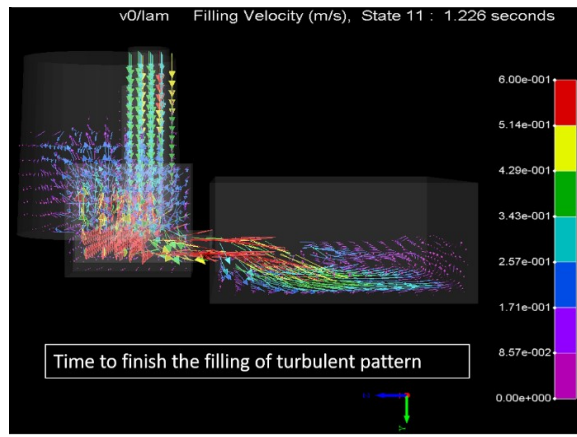

e)

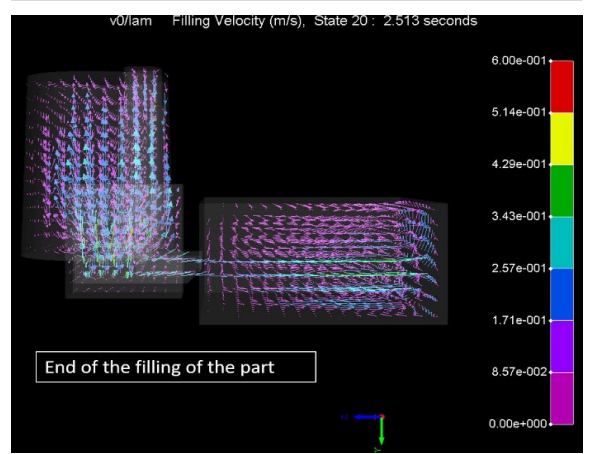

Fig. 7. Filling velocity of laminar pattern obtained by simulation on Quikcast: a) just before the filter; b) just after the filter; c) at the beginning of the filling of the part; d) time to finish the filling of turbulent pattern; e) at the end of the filling of the part

\subsection{Process parameters}

The mold is realized with a green sand representative of industrial conditions: $80 \%$ recycled sand and 20\% brand new sand. Some sodic clay (approximatively 9\%) and water are added to obtain the required mechanical characteristics [10], which are measured before each experiment. The variation ranges for each parameter of the mold are presented in Table 1.

Table 1

Impact of change of atmosphere on ceroxide formation

\begin{tabular}{cccc}
\hline $\begin{array}{c}\text { Compressibility, } \\
\mathbf{N} / \mathbf{c m}^{2}\end{array}$ & $\begin{array}{c}\text { Moisture, } \\
\mathbf{\%}\end{array}$ & $\begin{array}{c}\text { Clamping ability, } \\
\mathbf{\%}\end{array}$ & $\begin{array}{c}\text { Hardness, } \\
\mathbf{G F}\end{array}$ \\
\hline $14-18$ & $3.40-4.5$ & $50-70$ & $75-95$
\end{tabular}

The melting was done in an induction furnace $(2.5 \mathrm{kHz}$, $100 \mathrm{~kW}$ ) with silicon carbide melting pots. For each test, ingots of G20Mn5 (1.6220 in AISI designation) were heated up to their liquid state. The deoxidation was done directly in the melting pot when the pouring temperature of $1620^{\circ} \mathrm{C}$ was reached. In this study, the castings were done directly with a removable crucible (i.e., without using a ladle).

\subsection{Ceroxide characterization}

The ceroxide defect has been characterized by its maximum depth measured thanks to a continuous dial indicator and by the ratio between the surface affected by the defect and the total upper surface of Part 1 in Figure 5. Figure 8 presents the system used to measure the depth of the ceroxides.

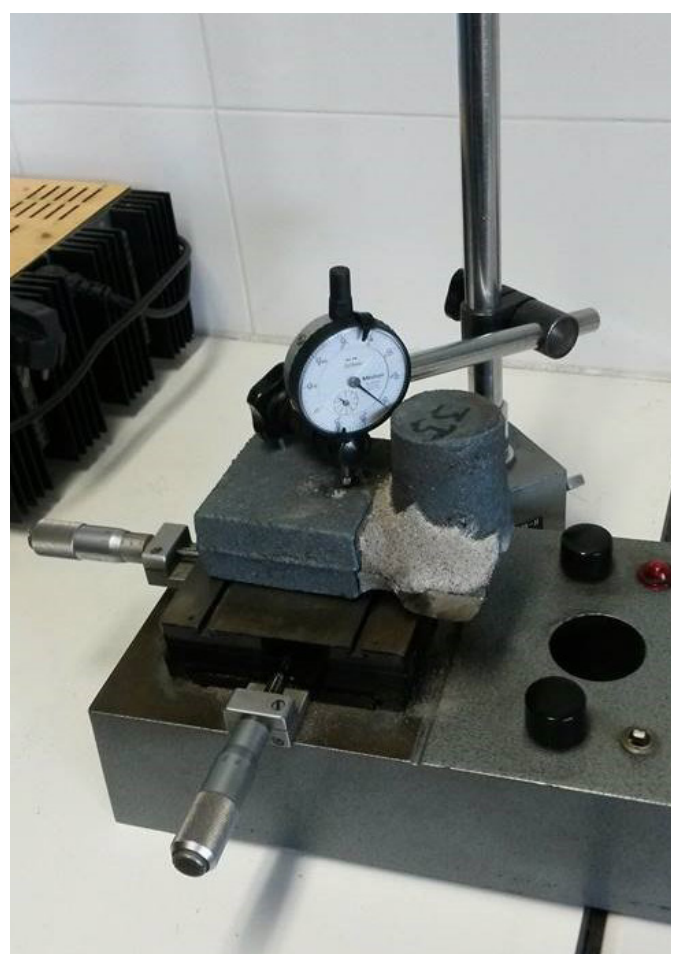

Fig. 8. Measuring tool for ceroxide depth 
For this characterization, the entire crater has been measured and only the maximum value of each sample has been conserved. These maximal depths are presented in Tables 2-4.

Table 2

Impact of deoxidizer of steel on ceroxide formation

\begin{tabular}{cccc}
\hline $\begin{array}{c}\text { Sample } \\
\text { Number }\end{array}$ & Description & $\begin{array}{c}\text { Area, } \\
\text { \% }\end{array}$ & $\begin{array}{c}\text { Depth, } \\
\mathbf{m m}\end{array}$ \\
\hline 0 & $\begin{array}{c}\text { Minimum value of } \\
\text { reference experiment }\end{array}$ & 10 & 2 \\
\hline 1 & Deoxidizer FeSiMnCa & 0 & 0 \\
\hline 2 & Deoxidizer FeSiMg & 14 & 3.4 \\
\hline 3 & Deoxidizer FeSiZr & 86 & 3.1 \\
\hline
\end{tabular}

Table 3

Impact of blind riser on ceroxide formation

\begin{tabular}{cccc}
\hline $\begin{array}{c}\text { Sample } \\
\text { Number }\end{array}$ & Description & $\begin{array}{c}\text { Area, } \\
\text { \% }\end{array}$ & $\begin{array}{c}\text { Depth, } \\
\text { mm }\end{array}$ \\
\hline 0 & $\begin{array}{c}\text { Minimum value of } \\
\text { reference experiment }\end{array}$ & 10 & 2 \\
\hline 4 & Blind feeder & 4.7 & 1 \\
\hline
\end{tabular}

Table 4

Mechanical characteristics of green sand

\begin{tabular}{cccc}
\hline $\begin{array}{c}\text { Sample } \\
\text { Number }\end{array}$ & Description & $\begin{array}{c}\text { Area, } \\
\text { \% }\end{array}$ & $\begin{array}{c}\text { Depth, } \\
\text { mm }\end{array}$ \\
\hline 0 & $\begin{array}{c}\text { Minimum value of } \\
\text { reference experiment }\end{array}$ & 10 & 2.0 \\
\hline 5 & Linseed oil & 28 & 5.3 \\
\hline 6 & Fuel oil & 3.0 & 0.9 \\
\hline
\end{tabular}

The characterization method of the ceroxides could seem overly simple. Nevertheless, the method is really efficient regarding the size and depth of the defects. Some roughness tests and volume measurements were done by different methods (for example, digital microscopy). Unfortunately, the size of the defects was too important to obtain good results.

\section{EXPERIMENTS}

As defined previously, the ceroxide's apparition seems to be due to the re-oxidation of aluminum during casting. To better understand its formation, some process parameters were changed at each step of the steel elaboration: molding, steel elaboration, and casting. Also, any test was done while changing two parameters: all of the parameters were tested independently of each other. The experiments were lead to control the apparition of the defect by three different ways:

- Changing the steel elaboration and particularly the deoxidation. To do this, three different deoxidizers without aluminum were tested to see its impact: FeSiMnCa, FeSiMg, and FeSiZr. Calcium, magnesium, and zirconium had to react with oxygen even more and play the same role as aluminum [11]. Obviously, deoxidation was done at the end of the steel elaboration just before pouring under the same conditions as in the reference test. The amount of each deoxidizer was calculated to have the same quantity of calcium, magnesium, and zirconium as that of aluminum. These experiments assumed that steel oxidation was constant during each melting, because the oxygen activity could not be measured in the bath.

- Reducing the amount of oxygen in the mold to limit the reaction with aluminum during the pouring. This parameter was not easy to change, because it was impossible to cast the part in a vacuum or inert atmosphere. The easiest way to do this was to use a blind feeder in the mold. The blind riser allowed us to limit the amount of oxygen: in fact, only the oxygen in the mold could react with the deoxidizer. This blind feeder kept the same modulus and geometry that the atmospheric riser had.

- Making another reaction in the mold during casting to consume the oxygen of the mold. As it was impossible to control the amount of oxygen in the mold, the idea was to consume it during the casting by another reaction. In this way, the probability of ceroxide apparition could be lower. To do this, two different experiments were made using a combustible as a coating at the surface of the mold. The combustibles (linseed oil and fuel oil) should burn during the pouring so to consume all of the oxygen.

\section{RESULTS AND DISCUSSION}

First of all, the experiments based on the change of deoxidizer gave heterogeneous results as shown in Figure 9 and Table 2. Deoxidation with zirconium using FeSiZr does not reduce the ceroxide formation: the default formed in this trial was even bigger and deeper than the reference one. The other two deoxidizers are in the same column of the periodic table, so their reaction of deoxidation should be more or less equivalent. Nevertheless, calcium is more reactive with oxygen than magnesium [11]; it is supposed to have a better yield of deoxidation and reduce more ceroxide formation. The results seem to confirm the hypothesis.

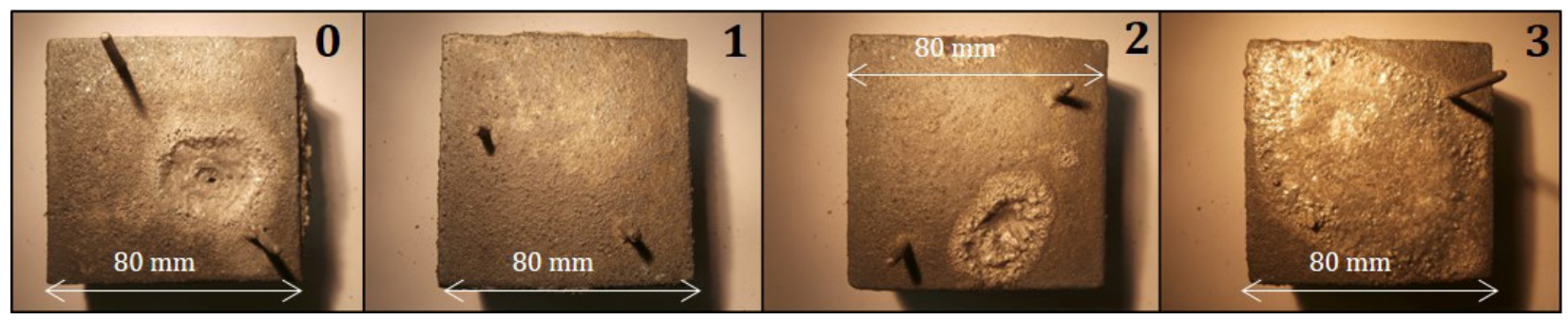

Fig. 9. Illustration of deoxidizer influence on ceroxide formation 
Deoxidation with magnesium gave a similar result as the reference test, while the deoxidizer with calcium avoided ceroxide formation. Seeing these results, the use of magnesium as a deoxidizer in an industrial foundry presents little interest when compared with aluminum due to the cost difference between the two products. Finally, the best way to deoxidize steel to remove ceroxide should be the use of a deoxidizer containing calcium. However, deoxidation with calcium is quite difficult and could be dangerous because of the important reactivity of this element with oxygen. Doing this under industrial conditions could present some risks for the steel quality, for example. This is why a deoxidation using a combination of an aluminum alloy and a small quantity of FeSiMnCa just before pouring could be the best solution.

The second parameter tested in this study was the impact of the quantity of oxygen in the mold able to react with aluminum. To show this, a modification of the mold was done by using a blind feeder that avoids a permanent contact between the metal and the ambient air during casting. As expected, this solution gave good results even if the limitation of the air flow on the mold was not enough to remove the ceroxide (see Table 3). At the same time, the blind feeder reduced the surface area impacted by the ceroxide as well as the depth of the default. This solution is already being used in most foundries, so it cannot be the only solution for avoiding ceroxide apparition. Nevertheless, this experiment highlights the role of oxygen in the mold/metal reaction that causes the ceroxide. Figure 10 presents the parts obtained with this test. The ceroxide looks like more of a classical skin defect of a foundry rather than a crater as described previously.

To end this study, some coatings were used in the mold to consume oxygen by combustion while casting the metal. The heat generated during the pouring had to react with the combustible and reduce the amount of oxygen in the mold.
Two combustibles were chosen due to their different air-requirements for combustion: linseed oil and fuel oil. The change of atmosphere in the mold was principally used to improve surface roughness [12] most particularly with a linseed oil or graphite coating. Finally, the results gave for both trials a ceroxide, but the surface and the depth were very different on each sample (see Table 4 and Figure 11). The fuel oil coating decreased the size and depth of the defect; this was contrary to the linseed oil, which increased both when compared to the reference. Nevertheless, the linseed oil coating improved the surface roughness of the sample on the surface not affected by the ceroxide corroborating [12].

The fuel oil coating gave promising results, but its utilization in an industrial context should be difficult due to security rules. Indeed, fuel oil burned during the metal casting, so some flames were visible by the riser on the top of the mold. It is possible to suppose that an important part of the oxygen present in the mold was consumed for fuel oil combustion and not to react with aluminum.

\section{CONCLUSION}

First of all, this study allows us to highlight a first-order parameter of ceroxide formation: the filling rate. Laminar flow is advised to reduce the probability of ceroxide appearance. However, if the filling rate is too important when generating a turbulent flow, ceroxides will be formed. So, the part design must be validated by simulation, and some element could be added in the mold to control the flow rate (such as a filter or regulator). A complement of this study could be determining the limit filling rate that systematically generates ceroxides.

Then, some parameters were tested to find a way of reducing ceroxides by simple methods and also to verify the hypothesis of their formation. Some results were really promising and should be investigated further.

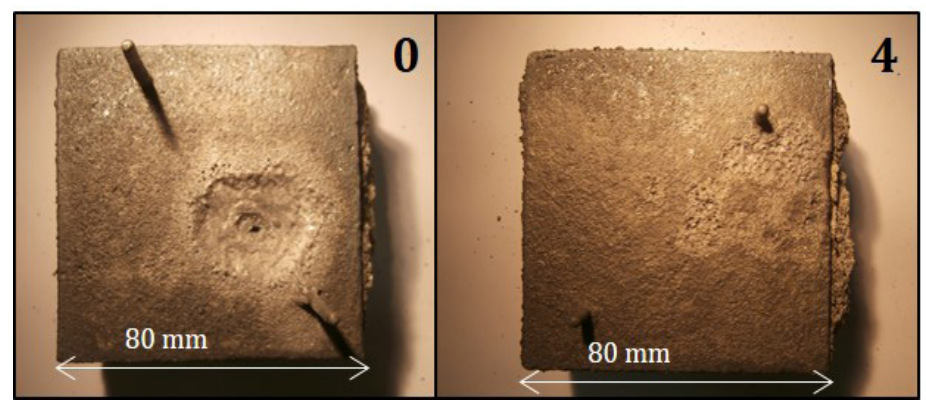

Fig. 10. Influence of blind feeder on ceroxide formation

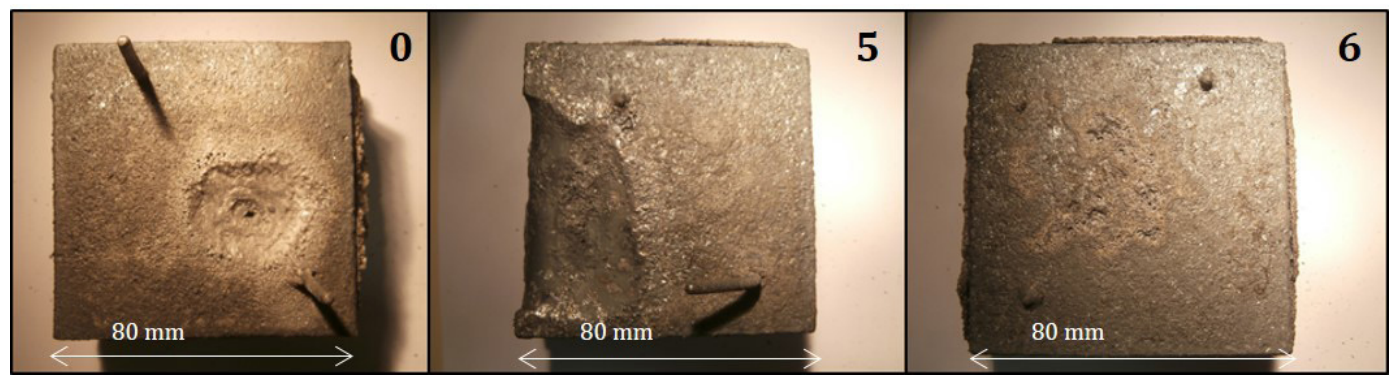

Fig. 11. Influence of different coatings on ceroxide formation 
Vingas [3] and Lyman [5] supposed that ceroxide formation was due to a mold/metal reaction between oxygen and the aluminum used to deoxidize the steel. Some results seem to confirm this hypothesis and show the role of oxygen and aluminum. Some process variations (principally on the amount of oxygen in the mold) allow for a reduction of the surface and depth of the default as the use of a blind feeder or a combustible coating on green sand. Changing the atmosphere of the mold to reduce the amount of oxygen should be a promising way to investigate. Nevertheless, security rules may not be compatible with this type of coating. The best way to confirm the role of oxygen on ceroxide formation would be to pour some parts in an inert atmosphere using argon or nitrogen gas and verify the lack of defect. This was not possible in the foundry lab of ENSAM Cluny (where the study was done).

Finally, the steel elaboration parameters were tested to show the impact of aluminum on ceroxide formation. This was done by changing the method of deoxidation using deoxidizers with zirconium, magnesium, and calcium at the end of melting. The results were really heterogeneous, and it was difficult to define a tendency. The lack of aluminum should normally lead to a lack of ceroxide according to [3] and [5]. Nevertheless, deoxidizers with zirconium or magnesium gave the same results (or worse) than the one containing aluminum. These elements could also react with oxygen while pouring and thus form ceroxides. The mold/metal reaction seems to be the same whichever deoxidizer is used.

The deoxidizer with calcium gave the best results of this study, completely removing the ceroxide. Considering the Ellingham diagram, calcium should react with oxygen as do aluminum, zirconium, or magnesium, and thus participate in the formation of a ceroxide. The lack of a ceroxide could be explained by the weak yield of calcium due to its strong reactivity with oxygen. This amount of calcium on steel could be enough to deoxidize the steel and contain a sufficient amount of calcium residual that is able to react with oxygen.

\section{Acknowledgments}

This study was financially supported by SAFE Metal.

\section{REFERENCES}

[1] Les poches et leur garnissage vis-à-vis des céroxydes. (1968). CTIF (Centre Technique des Industries de la Fonderie), Report $\mathrm{N}^{\circ} 1752$.

[2] Campbell J. (2015). Casting Alloys. In: Campbell J., Complete Casting Handbook. Metal Casting Processes, Metallurgy, Techniques and Design. Second Edition. Butterworth-Heinemann, $223-340$.

[3] Vingas G.J. \& Zrimsek A.H. (1965). US Patent no. 3216078 A, Process for casting steel and compositions of matter for use therein.

[4] Colbaut A. \& Beauvais P. (2005). Abreuvage de pièces massives en fonte coulées en sable à prise chimique. Fonderie-Fondeur d'Aujourd'hui, 250, 38-46.

[5] Lyman W.S., Boulger F.W. \& Briggs C.W. (1963). Character and source of the ceroxide defect on steel castings. Transactions of the American Foundrymen's Society, 71, 358-368.

[6] Beeley P. (2001). Defects in castings. In: Beely P., Foundry Technology. Second Edition, Butterworth-Henemann, 239-318.

[7] Mahaney J.K. Jr (1999). Advances in the production and use of steel with improved internal cleanliness. ASTM Special Technical Publication 1361.

[8] Chaume V. (2008). Internship Report, made with SAFE Metal for ESFF master degree.

[9] Belding P. (1971). The control of non-metallic inclusions in cast steel. Thesis for the degree of Master of Science. Oregon State University.

[10] Cuenin P. (1994). Moulage - Noyautage. Techniques de l'Ingénieur, Report M3512

[11] Datta P.K., Du H.L., Burnell-Gray J.S. \& Ricker R.E. (2005). Corrosion: Materials, Environments, and Industries, ASM Handbook, ASM International, 13B.

[12] Desbordes M. (1930). Le modeleur-mécanicien. Eyrolles edition 